\title{
MEMÓRIAS BORDADAS DE MULHERES E OS MOVIMENTOS MIGRATÓRIOS: SUAS IDENTIDADES CULTURAIS
}

RESUMO Neste artigo, vou tratar do papel da mulher nos movimentos migratórios; faço uma explanação sobre a necessidade de migrar, depois discuto um pouco sobre a cultura, que, na migração, sofre um empobrecimento, à medida que os migrantes precisam se desvincular de suas raízes e de como é necessário plantar outras. Por fim, trago dois exemplos de grupos de mulheres que bordam suas memórias, não deixando apagar suas identidades de origem, com suas 'escritasbordadas'

Palavras-chave: Mulheres. Memórias. Movimentos migratórios. Bordado. Cultura.

\section{ABSTRACT WOMEN'S EMBROIDERED MEMOIR AND THE MIGRATORY MOVEMENTS: THEIR CULTURAL IDENTITIES}

In this article, I will treat of the woman's paper in the migratory movements, I make an explanation about the need of migrating, later I discuss a little about the culture, that suffers an impoverishment in the migration, in the measure that the migrants need to divest of their roots and how it is necessary to plant others. Finally, I show two examples of womens's groups that embroider their memoirs not letting the identity of origin get extinguished, with their 'writtenembroidered'

Keywords: Women. Memories. Migratory movements. Embroidery. Culture.

RESUMEN MEMORIAS BORDADAS DE MUJERES Y LOS MOVIMIENTOS MIGRATORIOS: SUS IDENTIDADES CULTURALES

En este artículo trato el papel de la mujer en los movimientos migratorios, realizo una explicación respecto a la necesidad de migrar, 
luego discuto un poco sobre cultura, que en la migración pasa por un empobrecimiento, puesto que los migrantes deben desvincularse de sus raíces y surge la necesidad de plantar otras. Finalmente, comparto dos ejemplos de grupos de mujeres que bordan sus memorias no permitiendo que se borren sus identidades de origen, como sus 'escriturasbordadas'

Palabras claves: Mujeres. Memorias. Movimientos migratorios. Bordado. Cultura.

Neste artigo, vou tratar das memórias que florescem durante as trajetórias de vida ocorridas em processos migratórios, que existem na vida dos seres humanos, desde sempre. Esses 'praticantespensantes"1 buscavam, inicialmente, melhores terras para habitar, pelas mudanças de estações, em terras temperadas, pela ocupação de 'espaçostempos' diversos, na busca de emprego e um lugar onde pudessem morar e chamar de seu, inclusive as mudanças de bairro, comunidade. Quando penso em memória biográfica, trago para a discussão também a memória do tempo, a memória política, a memória do espaço, a memória do trabalho e a memória cultural, segundo Bosi (2014, p. 51).

Para Bosi (1994, p. 81) a memória como função social

É o momento de desempenhar a alta função da lembrança. Não porque as sensações se enfraquecem, mas porque o interesse se desloca, as reflexões seguem outra linha e se dobram sobre a quintessência do vivido. Cresce a nitidez e o número das imagens de outrora, e esta faculdade de relembrar exige um espírito desperto, a capacidade de não confundir a vida atual com a que passou, de reconhecer as lembranças e opô-las às imagens de agora.

Para Bosi (1994, p. 81), a memória como função social:

1 Termo apresentado por Oliveira (2012), indo além da ideia de Certeau que os chama somente de 'praticantes', mas coerente com o pensamento deste autor, que diz que esses criam conhecimentos e significações, permanentemente, no desenvolvimento de suas ações cotidianas.
É o momento de desempenhar a alta função da lembrança. Não porque as sensações se enfraquecem, mas porque o interesse se desloca, as reflexões seguem outra linha e se dobram sobre a quintessência do vivido. Cresce a nitidez e o número das imagens de outrora, e esta faculdade de relembrar exige um espírito desperto, a capacidade de não confundir a vida atual com a que passou, de reconhecer as lembranças e opô-las às imagens de agora.

O fenômeno migratório é fundamentalmente de caráter interdisciplinar, uma vez que permite interpretações de variadas ordens: demográfica, econômica, política, psicológica, cultural e/ou sociológica, e interfere diretamente na tessitura dos 'conhecimentossignificações'.2 No contexto das migrações, uma vertente que vem chamando a atenção dos estudiosos e demais interessados na temática da mobilidade humana e áreas afins é a questão de gênero.

$\mathrm{O}$ aumento da participação feminina, a partir de 1970, ocorre em um contexto de crescimento das migrações internacionais, a partir da segunda metade do século XX. Os migrantes contemporâneos, diferentemente de seus antecessores, contam com um sistema de comunicações e transporte mais barato e eficiente, o que diminuiu as distâncias e tornou mais

2 Este modo de escrever estes termos juntos e grafados - tais como os termos aprenderensinar, práticateoriaprática, discentesdocentes, espaçostempos, entre outros - é utilizado em pesquisas nos/dos/com os cotidianos e serve para nos indicar que, embora o modo dicotomizado de criar conhecimento na sociedade moderna teve sua significação e importância, esse modo tem significado limites ao desenvolvimento de esquisas nessa corrente de pensamento. 
frequentes os contatos entre a sociedade de origem e a sociedade de destino, com o aumento das comunicações o imigrante vai para seu destino conhecendo para onde vai, as muIheres iam com seu companheiro sem que thes fosse dado o direito de escolha, e nas pesquisas eram desconsideradas, portanto, durante algum tempo a mulher era considerada como dependente (ASSIS, 2007).

Pontuo as mulheres porque é histórica a dificuldade das mulheres em diferentes setores, mas principalmente o acesso à educação 'dentrofora' da escola. Sua ausência na escola (final do século XIX) era imposta e preconceituosa e a vida cotidiana feminina foi permeada pela rotina do lavar, passar, cozinhar etc., onde se entendia que não thes eram exigidos conhecimentos especializados. E nos estudos sobre migração elas eram vistas como dependentes, e hoje sabemos que grande parte dessas mulheres é a base forte do grupo.

O cotidiano dessas mulheres é cheio de pistas, indícios no dizer de Ginzburg (1987), deixadas nas diversas redes culturais, mesmo sendo desconsideradas nas pesquisas com seus trabalhos, na maioria das vezes manuais, é possivel sentir sua presença. Perceber também que a cada movimento migratório, essas mulheres criam novos caminhos e possibilidades, tais como: o cozinhar, o bordar, o dançar entre outros.

Elas tomam consciência, através dos movimentos feministas, dos medos da sociedade machista de perder o controle sobre uma situação imposta, vão abrindo mão da 'sagrada' missão de cuidar do 'lar', em nome de uma aquisição de conhecimento e da capacidade produtiva, procurando acalmar a todos e não entrando em conflito, buscando usar como tática a persuasão e o convencimento, como forma de luta pelos seus ideais; algumas delas buscam com seus trabalhos manuais conse- guir seu sustento e, no caso da migração, levar um pouco da cultura do lugar de origem por elas deixado, e resguardar as lembranças, essas chamadas por SimoneWeil (1996, p. 347) de enraizamento:

O enraizamento é talvez a necessidade da alma humana e uma das das mais difíceis de definir. o ser humano tem uma raiz por sua participação real, ativa e natural na existência de uma coletividade que conserva vivos certos tesouros do passado e certos pressentimentos do futuro.

E quando ocorre a migração, seja de um país distante, seja de um bairro, ocorre o desenraizamento que, segundo Bosi (2003, p. 178), "é a mais perigosa doença que atinge a cultura". Ela cita como exemplo o homem que trabalha na terra, ele planta o que come e, fora do seu lugar de origem, geralmente o primeiro trabalho é em uma fábrica e no lugar que mora não existe espaço para plantar a sua subsistência; necessita ir trabalhar em uma fábrica, essa seria a maior preocupação dos migrantes, se eles teriam como se alimentar. Outro exemplo é quando os filhos partem, tomam seus rumos, ainda que ligados afetivamente aos pais, se dispersam geograficamente. As bordadeiras retratam bem essa situação.

Foto 1 - Mãe guerreira criou os filhos depois de criado criou asas e voou

Filho criado Trabalho

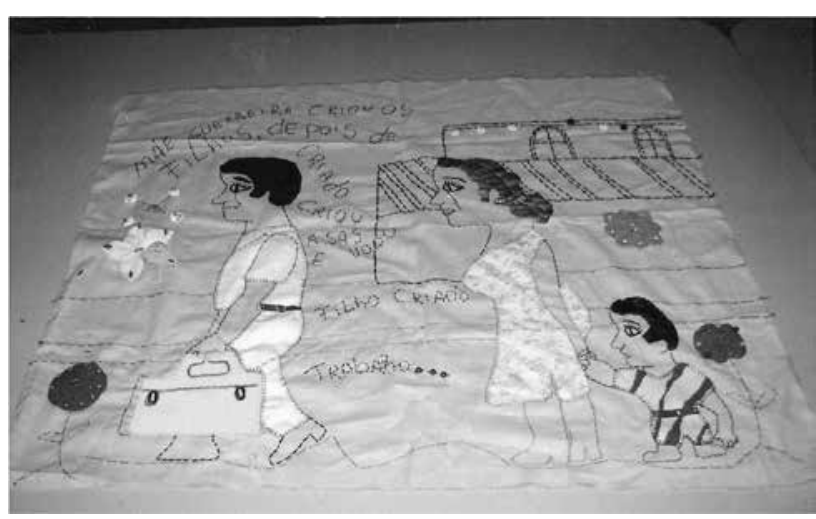

Fonte: Arquivo pessoal, 07/2006.

Bosi explica, quando diz que: 
A casa materna é uma presença constante nas autobiografias. Nem sempre é a primeira casa que se conheceu, mas é aquela em que vivemos os momentos mais importantes da infância. Ela é o centro geométrico do mundo, a cidade cresce a partir dela, em todas as direções. Fixamos a casa com as dimensões que ela teve para nós e causa espanto a redução que sofre quando vamos revê -la com os olhos de adulto. (1994, p. 435)

Por que as pesquisas agora se preocupam com a questão do gênero? Simplesmente porque as mulheres imigrantes hoje já chegam com diferentes capitais humanos; na sua maioria, com melhor nivel educacional e mais qualificação que as mulheres que chegaram em meados do século XX. Segundo Kodja (2004, p. 8):

\begin{abstract}
A história começa em meados do século XX. $\mathrm{Na}$ época, ainda sob a influência da aristocracia européia, em especial da inglesa, era um costume das famílias financeiramente privilegiadas bordar roupas de cama, mesa, banho e os enxovais das crianças. Era um hábito que sustentava o 'status' social e garantia uma demonstração de requinte e bom gosto. Esse trabalho, na cidade de Santos, era realizado por várias pessoas que recorriam a técnicas distintas, mas um dos grupos se destacava: o das bordadeiras da Ilha da Madeira. Como em Portugal, elas trabalhavam no linho, na seda natural, no organdi e no algodão. As peças de uso pessoal, que exibiam em suas casas, encantavam as senhoras que por ali passavam para fazer as suas encomendas. Os trabalhos perfeitos, resistentes, com barrados que alternavam pontos em relevo e espaços vazios, eram absolutamente originais
\end{abstract}

$\mathrm{Na}$ contemporaneidade, as mulheres imigrantes encontram mais oportunidades de emprego e possibilidades educacionais, as redes de 'conhecimentossignificações' são incontroláveis. Outro fator refere-se à legislação, que permite o divórcio e proíbe as discriminações de gênero, mas nem todas têm essas oportunidades, pois não chegam até elas seus direitos.

Entretanto o que há de comum nessas diferentes mulheres de origens e épocas diversas é que, apesar de uma melhor escolarização e qualificação, elas ocupam lugares tradicionalmente femininos, dos quais: o emprego doméstico ou o trabalho artesanal.

Alfredo Bosi (1997) escreveu um texto que fala bem da força do trabalho manual, intitulado "Os trabalhos da mão", ele diz, em um pequeno recorte:

Parece ser próprio do animal simbólico valer-se de uma só parte do seu organismo para exercer funções diversíssimas. A mão sirva de exemplo. A mão arranca da terra a raiz e a erva, colhe da árvore o fruto, descasca-o, leva-o à boca [...] A mão tateia com as pontas dos dedos, apalpa e calca com a polpa, raspa, arranha, escarva, escarifica e escarafuncha com as unhas. Com os nós dos dedos, bate. [...] A mão da mulher tem olheiros nas pontas dos dedos: risca o pano, enfia a agutha, costura, alinhava, pesponta, chuleia, cerze, caseia. Prende o tecido nos aros dos bastidores: e tece e urde e borda. (1997, p. 52-53)

Outro fator de relevância para além da questão do gênero é a origem nacional e social dessas mulheres; algumas são vitimizadas por uma cultura machista, na qual elas não têm direito a desejos e sonhos; outras são olhadas como objeto de desejo por sua beleza e sensualidade e são relacionadas à imagem da prostituição e da discriminação

Nesse contexto, a migração, articulada pelas redes sociais, também vai deixando de ser vista apenas como decisão racional de um indivíduo, para ser encarada como uma estratégia de grupos familiares, de amizade ou de vizinhança, em que as mulheres se inserem ativamente. As redes migratórias antes estudadas, como o deslocamento dos homens devido a diferentes ofertas de trabalho, hoje, são vistas a partir dos laços sociais que unem os migrantes, em sua maioria, redes baseadas em parentesco, amizade e origem comum. Quando essas redes são consideradas formadas apenas de homens, não se observam atributos de gênero e parentesco. 
As redes sociais auxiliam pessoas com poucos recursos, pouca experiência profissional e baixo nível de escolaridade, na migração. Existe um canal de solidariedade nessas redes, mas, por outro lado, existem as relações destorcidas daqueles que recebem os migrantes e exploram seus conterrâneos, provocando nessa rede de 'solidariedade' uma divisão de trabalho e um conflito étnico

Um fator que estimula esses movimentos migratórios internos são as desigualdades regionais que caminham com o processo de industrialização, com a expansão do capitalismo. A questão socioeconômica traz a comparação entre as regiões Nordeste e Sul do país e acaba por influenciar esses movimentos com efeito direto sobre o capital humano e a migração.

Nesse cenário de diferenças regionais, a socialização das mulheres, na maioria das vezes, é feita através da reprodução dos papéis de mães, avós, bisavós; no processo de trabalho doméstico, por falta de oportunidade. Uma característica ainda encontrada nos dias de hoje é o apadrinhamento de meninas que vivem na zona rural; elas são convidadas a trabalhar em 'casa de família' com a promessa de estudarem, mas é fato que, na maioria das vezes, isso não acontece, muitas são maltratadas e fogem para uma vida na rua, sem qualquer apoio.

Entender as práticas cotidianas das mulheres que participam desses movimentos, e uma delas era/é o bordado, desvendando espaços e 'maneiras de fazer'3 de algumas mulheres entendidas como 'praticantespensantes' dos cotidianos e nas redes sociais e educativas que se formam, nos faz perceber a presença destas em todos os contextos. Todas as mulheres são formadas por redes culturais (artísticas, tecnológicas, políticas etc.).

3 Maneiras de fazer constituem as mil práticas pelas quais usuários se reapropriam do espaço organizado pelas técnicas da produção sociocultural. (CERTEAU, 1994, p. 41)

\section{E por falar em cultura...}

Raymond Williams (1992) faz de seus primeiros estudos sobre cultura uma tentativa de compreender como o termo foi se constituindo e conformando determinados significados. 0 autor demonstra como o termo cultura foi sendo apreendido como abstração, como algo de absoluto. Ele identificou que o termo ganha autonomia, no século XX, mas suas bases são fixadas no século XIX.

Verifica que a ideia de cultura e seus desdobramentos passam a ser incorporados às nossas representações, prática intelectual e de alteridade, a partir das condições materiais que se transformam desde o século XVII. A cultura institui-se em um esforço por explicar, compreender e contemplar, de uma maneira geral, as mudanças socioeconômicas que deliberaram mudanças fundamentais no cotidiano dos indivíduos.

Williams (1992) verifica que essas mudanças, as mais significativas, a industrialização e a democracia, não foram de fácil aceitação: a primeira foi rejeitada, tanto no modo de produção com as máquinas quanto pelas relações de poder que o sistema sustentava; a segunda era negada a princípio, era vista como uma ameaça aos valores representativos dos donos do poder. Mas afinal quem eram os donos do poder? Santos (2000, p. 52) nos sinaliza, citando Foucault:

O poder disciplinar pelo contrário, não tem centro, é exercido em toda sociedade, é fragmentário e capilar; [...] exerce-se a partir da base e cria alvos próprios como veículos para seu exercício e parte de um discurso científico de normalização e padronização.

Nos movimentos migratórios também é significativa a presença do poder, seja na questão de gênero ou no poder econômico, mas os migrantes têm como característica a força da sua cultura que usam como forma de resistência. 
Do ponto de vista antropológico, a noção de cultura serviu em uma determinada época como instrumento colonizador e de desenraizamento. Antropólogos estudavam os povos para que em seguida os mesmos fossem dominados. Entretanto, na busca de compreensão desses povos, eles (antropólogos) perceberam a diversidade das culturas que poderiam estudar, tirando-as do anonimato, dando voz aos pequenos grupos, propiciando o surgimento de vários movimentos sociais (de mulheres, de afrodescendentes, de homossexuais, de sem terra etc.) (KUPPER, 2002, p. 288-289).

Williams (1992) analisa essas mudanças de significado do termo para que viéssemos a nos interessar em estudar culturas, como fizeram estudiosos do mundo inteiro, principalmente da Inglaterra. Vê-se, então, por meio do seu estudo sobre a formação do termo cultura, que ela instituiu práticas antes não realizadas e possíveis, estimulou mudanças nas relações entre sujeito e grupos sociais, criando identidades, novas relações, valores e modos de vida.

Segundo Williams (1992), a cultura produz a realidade, ao interagir com a força produtiva, constituindo o mundo real quando, com ele, se vale de meios materiais como: a língua, formas de escrever, sistemas eletrônicos e mecânicos de comunicação etc. Ele propõe descrever as relações sociais alteradas através do produto cultural, por meio do detalhamento interno e externo do produto cultural, identificando relações.

Acredito que tudo que é da ordem cultural está articulado ao social. A cultura não é uma abstração, é um conjunto de práticas, crenças, gostos, sons, sabores e saberes que é vivido, construído, reconstruído, em um determinado tempo histórico, em uma determinada sociedade. Quando o migrante sai do seu lugar de origem, ele busca, em um determinado grupo social, marcar suas lembranças, através da sua música, do seu alimento característico e por sua religião; as mulheres fazem seus artesanatos.
Para Williams (1992), os dados internos deverão evidenciar as relações do produtor e do produto cultural com as forças sociais e suas instituições e tradições. 0 estético está sempre associado ao social, por isso os traços internos de um produto cultural devem ser analisados em relação às condições sociais de possibilidade de produção. Trago para a discussão o que Santos (2000, p. 6) chama de 'caracter inacabado da racionalidade estético-expressiva', quando ele diz que:

(esse caráter) reside nos conceitos de prazer, de autoria e de artefactualidade discursiva. A colonização do prazer na modernidade ocidental deu-se através da industrialização do lazer e dos tempos livres, das indústrias culturais e da ideologia e a prática do consumismo. [...] Contudo, fora do alcance da colonização, mantevese a irredutivel individualidade intersubjetiva.

A cultura é alçada sempre como resposta ao tipo de vida no qual seu sujeito/autor/ator se encontra. As relações estão sempre refletidas nas alterações contidas na produção cultural, de modo a modificar a sua tradição e a própria organização social.

Não se trata de experiência pessoal ou de características de um grupo, mas de uma maneira comum de reagir ao modo de vida e de construir, interpretar, referendar modos de vida. Se cultura é um modo de vida global, portanto fazer sua análise representa descrever as inter-relações entre as práticas de 'conhecimentossignificações' que articulam e organizam a vida social e, permitindo que os migrantes refaçam suas vidas, possibilitam-lhes plantar novas raízes.

A vida social se processa, na perspectiva de Williams (1992), segundo um sistema organizado, onde não é possivel separar, desmembrar, isolar o produto cultural, a partir desse momento, trago para uma interlocução Stuart Hall (2003, p. 131-139), quando ele dialoga com Williams (1992), concluindo que “A análise da 
cultura é, portanto, a tentativa de descobrir a natureza da organização que forma o complexo desses relacionamentos".

Essa linha de pensamento, onde a Cultura, em suas várias formas, que se cruzam e misturam com todas as práticas sociais, possibilitando dar visibilidade aos 'praticantespensantes', por vezes esquecidos ou invisibilizados, permitindo-lhes fazer história, é a linha significativa dos Estudos Culturais, definidos por Hall (2003, p. 200), como aqueles que "abarcam discursos múltiplos, bem como numerosas histórias distintas. Compreendem um conjunto de formações, com suas diferentes conjunturas e momentos no passado".

Certeau (1994) reconhece que o fenômeno migratório constitui um espaço privilegiado para a análise de processos da construção das identidades, pois, por definição, é fenômeno de mudança social e cultural.

Para além da cultura, é preciso trazer a chamada cultura popular; Chartier (1995) diz ser a cultura popular uma categoria erudita, porque assim como a cultura erudita ela delimita os seus 'espaçostempos' e seus 'praticantespensantes' nomeiam seus 'saberesfazeres' como pertencentes à 'cultura popular'.

0 autor fala do caráter duplo da perspectiva da cultura popular, quando, ao mesmo tempo em que valoriza sua especificidade, criando um mundo com seus próprios símbolos, ela também acentua as diferenças hierárquicas da sociedade.

Chartier ressalta a importância dessas duas perspectivas para os historiadores, que as usam como "base para todos os modelos cronológicos que opõem uma suposta idade de ouro da cultura popular". E lembra do perigo metodológico de um pesquisador utilizar as duas perspectivas em um mesmo trabalho (1995, p. 180).

A cultura popular, certamente longe de se restringir aos historiadores, é compartilhada pelos sociólogos, folcloristas, estudantes de literatura, historiadores de arte e antropólogos sociais.

Outra divisão que ocorre é sobre o tipo de trabalho: o científico, destinado às classes sociais privilegiadas e o manual, que se diz característico das classes populares com seus saberes específicos do ponto de vista de um pequeno grupo.

A sociedade era/é dividida também na questão do gênero, e sinalizada por Santos (2000, p. 87), quando ele fala do gênero no seu trabalho:

A ciência moderna é sexista, visto que o universalismo da sua racionalidade cognitivo-instrumental se presta particularmente a transformar experiências dominantes (experiências de uma classe, sexo, raça ou etnia dominante) em experiências universais (verdades objetivas).

Santos (2000) fala que na pós-modernidade ocorre o desenvolvimento emancipatório de diferentes redes de relação; ele sinaliza para a busca de libertação feminina, através dos movimentos feministas, não visando apenas a questão do doméstico, mas trabalhando em outros espaços como os de produção, mercado, cidadania etc.

A partir do momento que a sociedade começa a sentir a necessidade de se colocar como um organismo, no qual cada sujeito tem sua função, de estudar, interpretar e avaliar as diferentes práticas culturais, em diversos contextos histórico-sociais, a análise da cultura passa a ser compreendida como forma global de vida e como experiência vivida de um grupo social; a cultura surge como um campo de luta em torno da significação social.

Uma das grandes questões para Chartier é não datar o surgimento e o aparecimento da cultura popular, mas de perceber momentos diferentes, em épocas distintas, onde relações complexas se dão de maneira que identidades/ações são reprimidas ou desenvolvidas (1995, p. 181). 
No processo de compreender os tantos movimentos de superação/compreensão da sociedade, Willliams (1992) sinaliza a diferença entre cultura vivida, que ele define como a cultura de uma época e um lugar determinado, somente acessivel para aqueles que vivem essa época e lugar, e a cultura de um período que é a registrada.

0 que vamos entendendo no momento presente é que o registro da cultura vivida tem uma história que só é possivel de ser contada se consultamos a memória dos praticantespensantes, se visibizamos os espaços/tempos dos que sabem e lembram por que viveram.

As práticas cotidianas nos permitem perceber que existe o que Ginzburg (1987, p. 12) chama de circularidade das culturas, não como a imagem de um ciclo, mas de uma espiral, onde a cultura popular e a erudita transitam nas diferentes redes culturais, independente de classes sociais, proporcionando uma negociação entre elas.

A negociação da cultura erudita com a cultura popular faz-se de maneira que a primeira se encontra em situação desfavorável em relação à segunda. A primeira tem lugares específicos, socialmente determinados, nos quais se difunde. A cultura popular, no entanto, é negociada no cotidiano, informalmente, e circula por lugares onde os homens e as mulheres de todas as idades circulam; com essa circularidade e transitoriedade os migrantes vão deixando suas lembranças, aprendem outras e formam outras mais.

Com o movimento de todas as redes de 'saberesfazeres', aos poucos foram surgindo possibilidades para a arte, principalmente através do uso das imagens, onde se vê aplicada a diversidade própria da época moderna, com as liberdades econômicas e políticas, e em meio a essas tensões da modernidade e as diversas possibilidades de conhecimentos se constituem as relações complexas.
O importante não é definir o que é uma cultura popular, mas a maneira pela qual essa cultura é apropriada pelos 'praticantespensantes'. Segundo Chartier, essa apropriação ${ }^{4}$ de uma rede de significados complexos "são tão ou mais geradoras de distinção do que as próprias práticas sociais" (CHARTIER, 1995, p. 184).

A partir das experiências incorporadas, com uma discussão das transformações culturais, sociais e econômicas ocorridas em meados do século XX, quando a migração se tornou uma realidade falada e mais tarde oficializada, foram se criando novas normas na maneira de viver e transmitir valores, de reconhecer o outro.

Neste período, houve um perfil de globalização, no qual se tentava a busca de uma padronização, mas é fundamental perceber, para estudos históricos, sociológicos e antropológicos culturais, a maneira como os sujeitos recebem, percebem, interpretam os modelos culturais impostos e como inscrevem neles suas próprias marcas, a partir de uma análise da variação do espaço, da época, de grupos sociais, ou seja, de modalidades e tipos de percepção e pertencimento dos sujeitos.

Agora, no início do século XXI, vai se percebendo a tentativa de fuga dessa padronização, de outras possibilidades de entrar no mercado de trabalho, mesmo que seja o informal, e a busca da identidade que se faz através de relatos, testemunhos culturais e estudos cada vez mais aprofundados da expressão cultural cotidiana. Carlo Ginzburg (apud PALLARES-BURKE, 2000, p. 289), declara:

Olhem para as classes populares e reflitam sobre o peso que nelas exerceram as decisões políticas conscientes, sobre a maneira como elas foram moldadas por aquelas decisões. Por isso é algo que me fascina entender como um simples evento pode mudar a sociedade.

4 Apropriação tal como a entendemos visa a elaboração de uma história social dos usos e das interpretações, relacionados a suas determinações fundamentais e inscritos nas práticas específicas que os constroem. (CHARTIER, 1995, p. 184) 
É nessa tentativa de fuga da padronização que o conceito de hibridação é útil, pois possibilita ao pesquisador perceber e utilizar termos como a mestiçagem, para descrever as fusões raciais ou étnicas, o sincretismo de crenças, e perceber a mistura entre o artesanal e o industrial, o culto e o popular, o escrito e o visual, nas mensagens midiáticas, segundo Canclini (2003).

Percorri esse caminho para entender melhor o foco do exemplo que vou trazer de migração, as culturas populares que hoje, início do século XXI, vêm aparecendo também como uma força econômica, na medida em que começaram a gerar empregos, principalmente com o grande número de migrantes, como as mulheres que se juntam em cooperativas para costurar, bordar e, vendendo seus trabalhos para indústrias da moda e até mesmo exportando, geram renda e se tornam muitas vezes mantenedoras da casa.

Outra possibilidade é o uso dessas práticas culturais populares para atraírem turistas, gerando trabalho direto e indireto para a população, diminuindo o êxodo para os grandes centros urbanos, e propiciando uma qualidade de vida. E para além do fator econômico, levar os indivíduos a se interessarem em solidificar suas histórias, suas marcas, suas referências personalizadas, o que fica dificil em produtos industrializados.

\section{A migração das Mariquinhas de um bairro para outro}

Toda essa escrita sobre cultura popular foi para trazer o grupo de mulheres migrantes que escolhi destacar no meu texto, o qual eu conheci durante a minha pesquisa para o mestrado em 2007 'As Mariquinhas'. Essas mulheresbordadeiras fazem parte de um grupo de 375 famílias sem teto, que realizaram manifestações no centro de Belo Horizonte, no início da década de 1990, depois da invasão de uma área, a fazenda
Marzagânia, próxima ao município de Sabará, onde viveram durante onze meses em condições sub-humanas e de onde foram expulsas. Elas partiram para a ocupação, com lonas, de um terreno no bairro Juliana, região norte de Belo Horizonte, onde posteriormente receberam lotes, construíram casas e hoje vivem.

O trabalho dessas mulheres começou quando as mesmas ficaram incomodadas de nada ser feito por elas. Na escola da comunidade - é bom dizer que, enquanto essas mulheres estavam acampadas, seus filhos sofriam discriminação e não eram aceitos nas escolas da prefeitura, por falta de comprovante de residência thes era negado, pela própria prefeitura - acontecia um projeto de artes para as crianças na paróquia mais próxima. Nele, elas desenhavam, pintavam. Esse fato aconteceu porque foram permitidas inúmeras relações complexas entre os 'praticantespensantes' das redes educativas de 'dentrofora' da escola.

Um grupo de mulheres que tinha seus filhos e netos no projeto resolveu pedir ao produtor cultural do mesmo - Wilson Avelar - uma oportunidade para que elas pudessem aprender alguma coisa. Ele as convidou para participar da oficina de desenho, o que em nada as agradou. Foi nesse momento que surgiu a ideia do bordado, que se concretizou com o auxílio de uma freira, que lhes ensinou alguns pontos. A partir daí, essas mulheres deram continuidade ao grupo de bordado, hoje não mais com o produtor Wilson, e também não mais utilizando o espaço da igreja. Essas mulheres consequiram que fosse construído um conjunto habitacional, no qual cada uma teve direito a sua casa, a seguir conseguiram, junto com a comunidade do Conjunto habitacional Mariquinhas, construir uma creche para atender as crianças da comunidade e é ali que elas se encontram, de segunda a quinta-feira, das 7h30min às 16h, para bordar, conversar e lembrar - produzir, 'inventar o cotidiano'. O encontro em imagem. 
Foto 2 - 0 grupo das Mariquinhas trabalhando

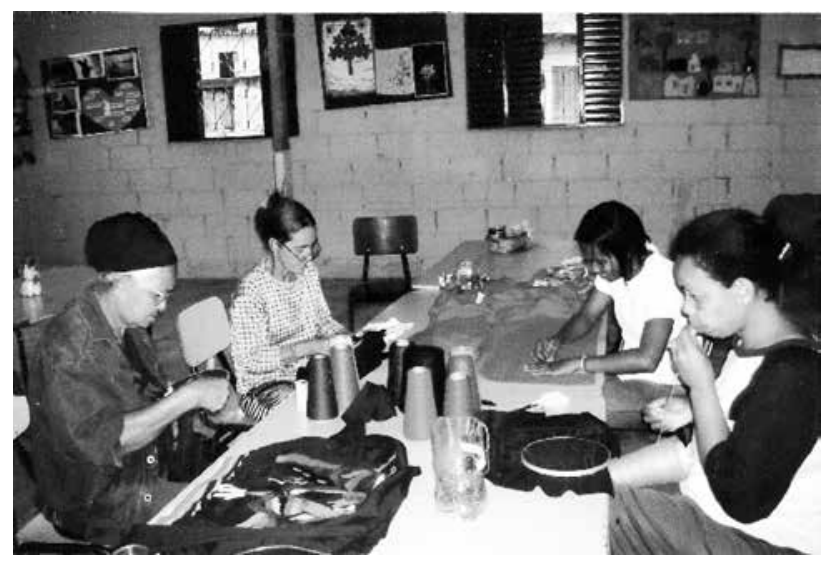

Fonte: Arquivo pessoal, 07/2006.

Quem coordena o grupo é a Dona Ivone Barbosa. Todas a respeitam e é ela quem distribui tarefas: Maria Auxiliadora é a bordadeira mais idosa, analfabeta, ela diz que com o bordado ela expressa o que sente e diz que o pano é meu papel, a agulha e a linha meu lápis; Maria Terezinha tem quatro filhos e retrata nos seus bordados sua vida familiar, o problema com o marido que antes bebia, o orgulho dos pais e o amor aos filhos; Elizabeth Márcia borda suas alegrias, pois não gosta de registrar seus problemas e, apesar da pouca idade, já tem dois netos e divide seu tempo entre a cooperativa e a cuidado dos netos, o que é facilitado pela localização de sua casa, pois mora em frente à creche; Lucimar Mara é a responsável por todos os riscos, as amigas dizem o que desejam bordar e ela risca a mão livre, direto no pano com giz de cera e, quanto aos seus bordados, são declarações de amor e a maior parte declara uma procura do companheiro, pois já casou quatro vezes, mas diz só agora ter encontrado o homem certo; Sonia Roque borda o amor sempre, o amor aos filhos, aos amigos, aos companheiros, à terra, à casa, às amigas, apesar da sua triste história. Sonia vivia nas ruas, não conheceu os pais, até que foi recolhida e ficou em uma instituição para menores; ao sair do colégio, casou-se, teve um filho e seu marido morreu; partiu, então, para a luta pela posse do terreno e construiu sozinha sua casa de oito cômodos; engravidou mais uma vez e foi abandonada pelo pai da criança; apesar de tudo isso, seus bordados são sempre uma mensagem de amor e esperança.

Essas mulheres passaram por todo tipo de violência, física ou moral. No entanto, na luta pela cidadania através de suas migrações, perpassam as transformações ocorridas no papel da mulher na sociedade, dão muitas lições e alcançaram vitórias como o terreno e a construção da casa própria, bem como a organização da cooperativa e a venda de seus trabalhos, além do sentimento de pertencimento tão caro para quem é migrante.

As Mariquinhas já foram entrevistadas por várias revistas nacionais e seus trabalhos já participaram de várias exposições, dentre elas uma em Paris. 0 bordado comemorativo.

Foto 3 - Bordado comemorativo da posse das casas. "O sonho da minha casa própria"

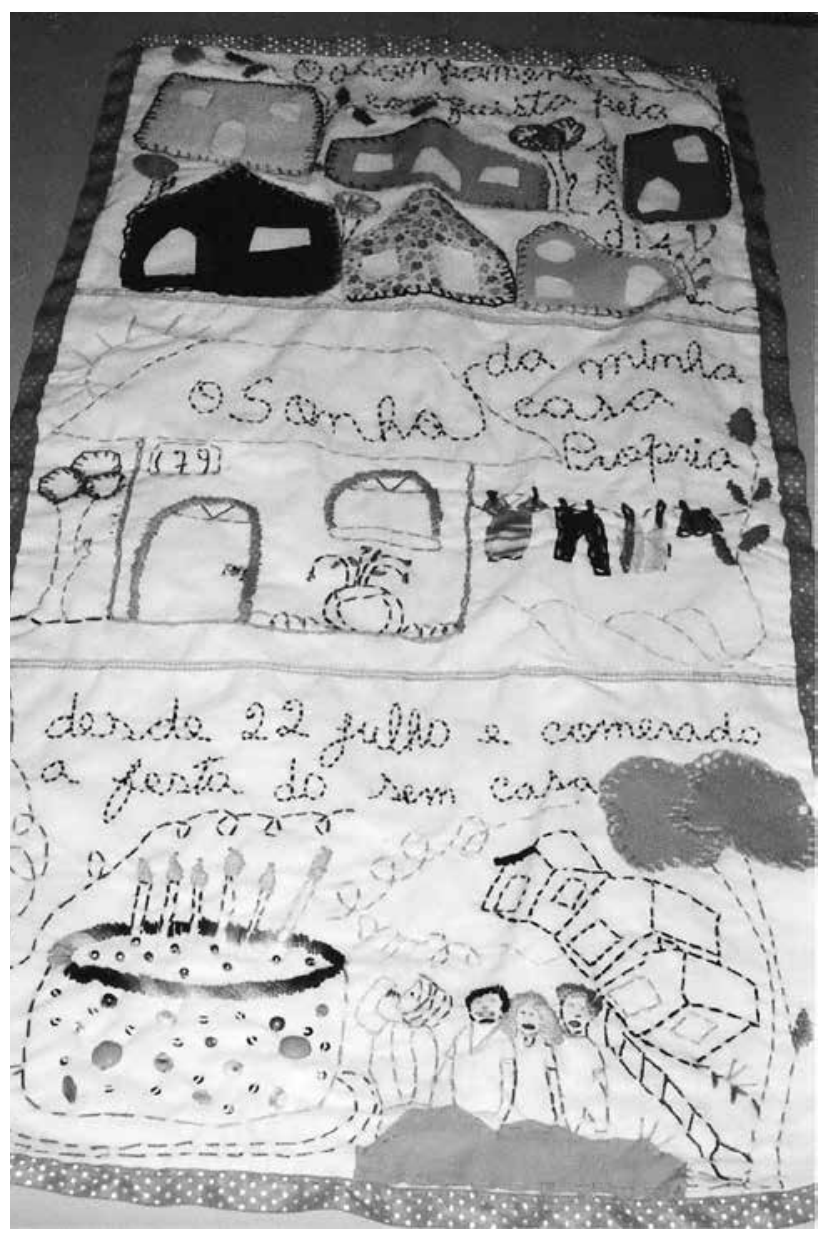

Fonte: Arquivo pessoal, 22 julho 2006. 


\section{As imigrantes da Ilha da Madeira (Portugal)}

O outro grupo que conheci, esse apenas por uma reportagem de Gisela Kodja, para um jornal da região de Santos, Estado de São Paulo. Seus maridos vinham na frente com a esperança de um Mundo Novo, e depois mandavam carta para chamá-las, contam essas senhoras portuguesas, e falam também da dificuldade que foi fazer essa viagem de, no mínimo, onze dias de navio. Elas contam que os morros de Santos, em São Paulo, tiveram muitos imigrantes portugueses como moradores do local, por volta do século XVII. Elas relatam que as mulheres foram fundamentais para a economia familiar, com os borbados que aprenderam na sua terra natal e que fizeram grande sucesso entre os brasileiros. Elas relatam que nos morros de Santos elas se sentiam mais próximas da terra natal, visto que a Itha da Madeira tem características montanhosas e, na busca por uma melhor identificação, lá ficaram; a geografia de Santos, com seus paredões de morros, atraiu muitos imigrantes portugueses. No começo dessa jornada, participavam 300 mulheres bordadeiras o que trouxe um boa fonte de renda para os moradores do morro de São Bento. Atualmente, ainda resistem bordando, três mulheres, dentre elas apenas uma é brasileira, mas filha de portugueses.

Elas contam que, enquanto os maridos trabalhavam fora, elas cuidavam da casa e dos filhos e era o dinheiro do bordado que complementava a renda; durante muitos anos, seus bordados enfeitavam os enxovais das famílias mais ricas. Com a mudança, na década de 1960, do uso do material, deixando de trabalhar o linho para utilizar o tergal, referência americana, elas precisaram se adaptar, usaram material mais simples, mas não menos caprichoso.

Hoje, com as mulheres trabalhando fora, o conhecimento passado de mãe para filha está se perdendo, mas ainda existem mulheres interessadas na cultura madeirense. Uma vez por semana, elas se encontram no Centro Cultural Esportivo do Morro de São Bento e passam adiante os segredos dessa tradição

Foto 4 - Grupo de bordadeiras do morro de São Bento, sem autor e data

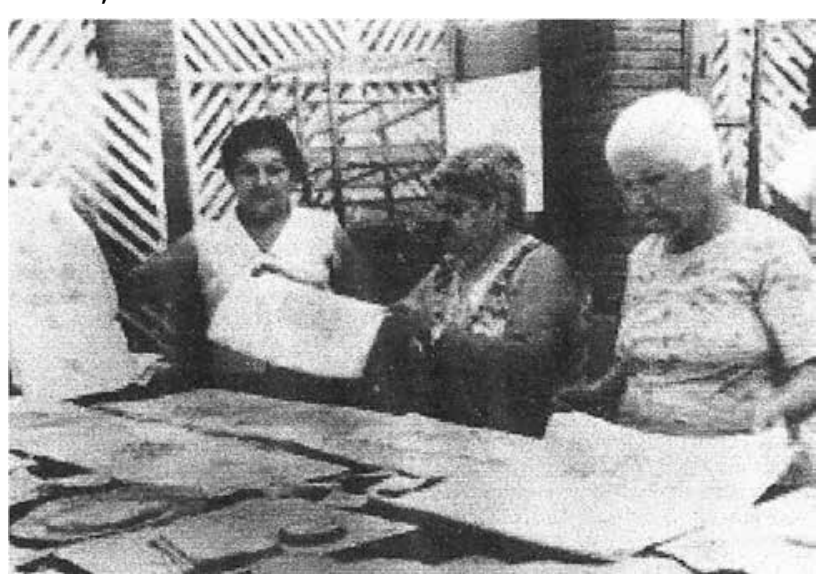

Fonte: Disponivel em: <http://www.novomilenio.inf.br/ santos/h0134h.htm>. Acesso em: 01 mai. 2013.

A vida dessas mulheres, que ficaram conhecidas como bordadeiras, já está registrada em um livro escrito pela jornalista Gisela Kodja. "Além de serem imigrantes, terem vindo acompanhando seus maridos que precisavam de oportunidade de emprego para manter as famílias, mas elas trouxeram seu próprio trabalho. Elas não vieram só como acompanhantes, elas também tinham alguma coisa para oferecer para o país", explica a jornalista (KODJA, 2013). A história das senhoras portuguesas vai ganhar as telas do cinema, em um documentário realizado por produtores de Santos. "Esse documentário pretende ser um grande registro cultural da vida dessas bordadeiras, da luta das bordadeiras representando toda a comunidade portuguesa, na colonização e na ocupação do morro do São Bento", conta o produtor do documentário João Guilherme Peixoto (KODJA, 2013).

\section{A memória da 'escritabordada'}

Para trabalhar com a cultura escritabordada e a cultura oral preciso deixar claro que percor- 
ro uma trajetória teórico-metodológica onde busco compreender como a tessitura de 'conhecimentossignoficações' se dá.

A cada dia, surgem novas e diferentes tecnologias e concomitantemente a discussão em torno dos artefatos utilizados no processo de 'ensinoaprendizagem'; isso exige que, no processo de formação de professores, seja possível, entre outras questões, pensar e discutir as relações da escrita com a formação de pensamento e a linguagem.

Perceber a oralidade da narrativa que se expressa através da escrita ou contando histórias, e como é que as mulheres se apropriam da escrita utilizando as normas da cultura oral, através dos seus bordados. Essas mulheres migrantes trabalham com a lembrança social, política, entre outras.

Certeau (2014, p. 202) explica que: “A oralidade se insinua sobretudo como um desses fios de que se faz, na trama - interminável tapeçaria - de uma economia escriturística".

0 autor acima citado fala da presença da oralidade na arte de escrever. Ao estudar a questão do gênero, percebi que a dicotomia no ato de escrever e a oralidade era uma constante, às mulheres era negado o aprendizado da escrita, em nome de um trabalho manual, e hoje fica claro que a oralidade é fundamental na escrita e que as mulheres de algum modo escreverambordaram da maneira que thes foi permitida. Certeau reforça, ao dizer que

Referir-se à escritura e à oralidade, quero precisar logo de saída, não postula dois termos opostos, cuja contrariedade poderia ser superada por um terceiro, ou cuja hierarquização se pudesse inverter. $(2014$, p. 202-203)

As palavras por si só reforçam a idéia do textobordado, senão vejamos: tessitura, texto, rede, teia. E como todo texto, utilizo vários fios que serão ou não retrançados a outros fios. Machado (2001, p. 14-15) sinalizou e complementou dizendo que: "Várias das palavras, que se usam para designar o texto e a escrita, derivam de outro conjunto de atividades tradicionalmente femininas, a fiação e a tecelagem" [e o bordado também].

Machado (2001) faz um paralelo da atividade de fiar e tecer com a produtividade feminina. Ela lembra que é histórica a participação das mulheres na produção têxtil até o surgimento do tear mecânico, na segunda metade do século XVIII. E diz também que:

nem só os tecidos, eram o resultado direto do trabalho feminino com os fios. Também os bordados, as rendas, o crochê, o tricô, o frivolité, o macramé e tantos outros termos herdados do francês para designar finos lavores [...] (2001, p. 30)

O estudo da história da cultura escrita permitiu perceber uma especificidade da história cultural, cujo objetivo está na interpretação das práticas sociais de escrever e ler, segundo Castillo Gómez (2003, p. 93). Entender a escrita, para além de um processo gráfico, pesquisar suas funções, 'saberesfazeres' e em que 'espaçostempos' elas acontecem, propicia testemunhos escritos, alguns bordados de uma determinada sociedade, independente de técnicas e materiais, no câmbio de relações simbólicas e materiais.

Os bordados escritos ficam, no entanto, a meio caminho entre a escrita e a expressão oral, já que, usando letras para se expressar, escritas primeiro e depois bordadas por cima, em geral, têm a ver com modos de expressão, comumente, relacionados à oralidade. E estudar bordado é de alguma forma estudar a escrita, uma vez que o bordado é uma espécie de escrita, no qual aparece, muitas vezes, a escrita mesmo. 0 bordado é uma forma entre escrita e oralidade. 0 textobordado fica, no meu entender, nesse meio caminho da oralidade e da escrita, através de seus alinhavos e tessituras de ideias e sonhos. 
[...] ouvimos menções ao 'texto' de uma enunciação oral. 'Texto', cuja raiz significa 'tecer', é, em termos absolutos, mais compativel etimologicamente com anunciação oral do que 'literatura', que etimologicamente se refere a letras (literae) do alfabeto. 0 discurso oral tem sido geralmente considerado, até mesmo em ambientes orais, como tecer ou alinhavar - rrhapsõidein, 'fazer rapsódias' significa basicamete em grego 'alinhavar canções'. Mas na verdade, quando na cultura escrita se usa hoje o termo 'texto' para fazer referência à apresentação oral, está-se pensando em termos de uma analogia com a escrita. (p. 22) [...] apresentando disposições visuais de letras [signos] e/ou palavras que por vezes podem ser vistas, mas não lidas em voz alta, mas das quais nenhuma pode ser apropriada sem alguma consciência do som verbal. (ONG, 1998, p. 147)

Castillo Gómez (2002, p. 26) diz que basta olharmos rapidamente alguns materiais para percebermos que existe uma história a ser contada através desse suporte; ela cita alguns como cartas de amor, diários, livros de memórias e cadernos e diários de escola, entre outros. A partir dos cadernos escolares, podemos estudar o currículo das escolas, o que era privilegiado, e principalmente como era tratada a questão do gênero, os cadernos escolares têm sido de fundamental importância para as pesquisas.

Ver a linguagem como um fenômeno oral parece ser inevitável e óbvio. Os seres humanos comunicam-se de inúmeras maneiras, fazendo uso de todos os seus sentidos: tato, paladar, olfato e especialmente visão, assim como audição (ONG, 1998, p. 15). Para as bordadeiras, enquanto thes for permitido bordar, vai valer a pena viver cada pano bordado: lembranças são revividas e, dessa maneira, tecem sua história. Por vezes remendada por uma lembrança há muito esquecida, dolorida, mas fundamental, na formação desse novo grupo social. Trago Bosi para pensar sobre o que é identidade para essas mulheres. Ela afirma que:
A comunidade familiar ou grupal exerce uma função de apoio como testemunha e intérprete daquelas experiências. 0 conjunto das lembranças é também uma construção social do grupo em que a pessoa vive e coexistem elementos da escolha e rejeição em relação ao que será lembrado. (2003, p. 54)

O que significa para essas mulheres serem bordadeiras? Foi a pergunta que me fiz durante a minha escrita. Percebi que bordar nunca é um ato solitário, mesmo que elas estejam sozinhas, suas lembranças e esperanças as acompanham. Para as bordadeiras, enquanto Ihes for permitido bordar, vai valer a pena viver cada pano bordado: lembranças são revividas e, dessa maneira, tecem sua história, por vezes remendada por uma lembrança há muito esquecida, dolorida, mais fundamental.

Esse tipo de trabalho permitiu que as mulheres se organizassem em grupos para se dedicarem a sua arte. Elas passavam/passam os dias reunidas, bordando, contando histórias, conversando e transformando o bordado em escrita. A escrita expressa em bordado:

Na memória política, os juízos de valor intervêm com mais insistência. 0 sujeito não se contenta em narrar como testemunha histórica 'neutra'. Ele quer também julgar, marcando bem o lado em que estava naquela altura da história, reafirmando sua posição ou matizando-a. (BOSI, 1994, p. 453)

As dificuldades enfrentadas são muitas, mas o migrante é capaz de criar o que Santos (1999) chama de "espírito alerta", pelo qual ele busca novas maneira de ser e viver, que reorganizem suas expectativas para o futuro na medida em que ele se reconhece dentro da nova rede social que o cerca. Entretanto, na questão da migração, surge um sentimento de compreensão, no sentido de entender como agir diante de determinados processos condicionantes, que possam provocar uma sensação de impossibilidade, tais como: restrições 
ou condições em termos de identificação sociocultural e, ainda mais forte, a questão socioespacial. Para que haja um sentimento de pertencimento, esse migrante precisa fixar-se em um espaço próprio e se sentir confortável para mover-se no novo território que ele escolheu como seu destino. Alguns fatores determinam se esse sentimento será positivo ou negativo, na tentativa ou interesse em fazê-lo.

\section{Referências}

ASSIS, Gláucia de Oliveira. Mulheres migrantes no passado e no presente: gênero, redes sociais e migração internacional. Estudos Feministas, Florianópolis, 15(3): 745-772, set./dez. 2007. Disponivel em: $<$ www.scielo.br/pdf/ref/v15n3/a15v15n3.pdf>. Acesso em: 23 jul. 2017.

BOSI, Alfredo. 0 trabalho das mãos. In: BOSI, Alfredo. 0 ser e o tempo da poesia. São Paulo: Cultrix, 1997. p. 52-56.

BOSI, Ecléa. Memória e sociedade - Lembranças de velhos. São Paulo: Companhia das Letras, 1994.

O vivo da memória: ensaios de psicologia social. São Paulo: Ateliê Editorial, 2003

Narrativas sensiveis sobre grupos

fragilizados: entrevista para Mariluce Moura. Pesquisa FAPESP, São Paulo, Fundação de Amparo a Pesquisa do Estado de São Paulo, n. 218, p. 47-53, abr. 2014.

CANCLINI, Nestor Garcia. Culturas híbridas. 4. ed. São Paulo: Editora da Universidade de São Paulo, 2003.

CASTILLO GÓMEZ, Antonio. História da cultura escrita. Ideas para el debate. Revista Brasileira de História da Educação, Campinas, Autores Associados, SBHE, n. 5, p. 93-125, jan./jul. 2003.

CERTEAU, Michel de. A invenção do cotidiano: 1. Artes de fazer. 2. ed. Petrópolis, RJ: Vozes, 2014.

CHAGAS, Claudia. Memórias bordadas nos cotidianos e nos currículos. 2007. 101 f. Dissertação (Mestrado em Educação) - Programa de Pós-Graduação em Educação - PROPEd, Universidade do Estado do Rio de Janeiro, Rio de Janeiro, 2007.

CHARTIER, Roger. Cultura popular - revisitando um conceito historiográfico. Tradução de Anne-Marie Milon Oliveira. Estudos históricos: Culture and urban history, Rio de Janeiro, v. 8, n. 16, p. 179-192, 1995.

GINZBURG, Carlo. 0 queijo e os vermes - 0 cotidiano e as idéias de um moleiro perseguido pela Inquisição. Tradução de Maria Betania Amoroso. São Paulo: Companhia das Letras, 1987.

HALL, Stuart. Estudos Culturais, dois paradigmas. In: HALL, Stuart. Da Diáspora - Identidades e mediações culturais. Belo Horizonte: Editora UFMG, 2003. p. 131-159.

KODJA, Gisela. Bordadeiras do Morro São Bento: memória, trabalho e identidade. 2004. 200 f. Dissertação (Mestrado em Gerontologia) - Faculdade de Ciências Sociais, Pontifícia Universidade Católica de São Paulo, São Paulo, 2004.

Bordadeiras de Santos viram tema de livro e documentário. Reportagem do jornal 0 Globo. Disponivel em: <http://g1.globo.com/sp/santos -regiao/noticia/2013/05>. Acesso em: 01 mai. 2013.

KUPPER, Adam. Cultura, diferença, identidade. In: KUPPER, Adam. Cultura: a visão dos antropólogos. Tradução de Mirtes Frange de Oliveira Pinheiros. Bauru, SP: EDUSC, 2002. p. 287- 311.

MACHADO, Ana Maria. O Tao da teia - sobre textos e têxteis. In: MACHADO, Ana Maria. Texturas: sobre leitura e escritos. Rio de Janeiro: Nova Fronteira, 2001. p. 11-51.

OLIVEIRA, Inês Barbosa de. Currículos e pesquisas com os cotidianos: o caráter emancipatório dos currículos 'pensadospraticados' pelos 'praticantespensantes' dos cotidianos das escolas. In: FERRAÇO, Carlos Eduardo; MAGALHÃES, Janete Carvalho. (Orgs). Currículos, pesquisas, conhecimentos e produção de subjetividades. Petrópolis, RJ: DP et Alli, 2012. p. 47-70.

ONG, Walter. Oralidade e cultura escrita: a tecnologização da palavra. Tradução de Enid Abreu Dob- 
ránszky. Campinas, SP: Papirus, 1998.

PALLARES-BURKE, Maria Lucia. Carlo Ginsburg. In: PALLARES-BURKE, Maria Lucia. As muitas faces da história. São Paulo: UNESP, 2000. p. 269-306.

SANTOS, Boaventura de Souza. A crítica da razão indolente: contra o desperdício da experiência. São Paulo: Cortez, 2000.

SANTOS, Milton. A natureza do espaço: técnica e tempo, razão e emoção. São Paulo: Hucitec, 1999.

WEIL, Simone. A condição operária e outros estudos sobre a opressão. Rio de Janeiro: Paz e Terra, 1996.

WILLIAMS, Raymonds. Cultura. São Paulo: Paz e Terra, 1992.

Recebido em: 20.07.2017

Aprovado em: 30.03 .2018

Claudia Regina Ribeiro Pinheiro das Chagas é Doutora em Educação pelo PROPed /UERJ. Bolsista CAPES na modalidade PNPD pelo Programa de Pós-Graduação em Educação Processos Formativos e Desigualdades Sociais, da Faculdade de Formação de Professores, da Universidade do Estado do Rio de Janeiro (PPGEDU-PFDS.FFP/UERJ), Integrante do Grupo de Pesquisa Currículos, Redes Educativas e Imagens. e-mail: chagas.prof@gmail.com

Rua Cachambi, no 464, Cachambi, Rio de Janeiro. CEP: 20771-632. Telefones: (21) 32984916 e (21) 998358779 